\title{
Eye gaze technology: A South African perspective
}

\author{
Karin van Niekerk \\ Kerstin Tonsing \\ Centre for Augmentative and Alternative Communication \\ University of Pretoria \\ South Africa
}

Contact details:

karin.vanniekerk@up.ac.za

kerstin.tonsing@up.ac.za

\begin{abstract}
Purpose: Based on the bioecological model by Bronfenbrenner, this paper will provide a broad perspective on factors that need to be taken into account in order to facilitate communication and participation in preliterate children making use of electronic AAC systems accessed through eye gaze.
\end{abstract}

Method: Two case studies of children who have been provided with the technology described are presented. The case studies were analysed using the four nested systems of the ecology as a framework to describe not only the environment, but also the processes and interactions between the persons and their context.

Results: Risk and opportunity factors are evident at all levels of the ecology.

Conclusions: While a good fit between the person and the technology is an essential starting point, additional factors pertaining to the partner, the immediate environment as well as meso-, exo- and macrosystemic issues (such as societal attitudes and funding sources) have a significant influence on benefits derived. In resource-limited environments, the lack of support at more distal levels of the ecology (meso-, exo and marosystemic levels) seems to be a factor that differentiates these environments from more resourced ones. 


\section{Keywords}

Augmentative and alternative communication, children with severe physical disabilities, eye gaze access, graphic symbols, little or no functional speech.

\section{Implications for Rehabilitation:}

- Within resource-limited environments lack of support from wider ecological systems pose a risk to the implementation of eye gaze technology.

- Attempts to improve collaboration between all role players could provide the opportunity for the establishment of an integrated plan for intervention and set the stage for information sharing and multiskilling between role players.

- Intervention should not only be aimed at addressing the needs of the individual client and their family, but also focus on building community capacity that could provide support to others.

\section{Introduction}

Eye gaze technology can provide people with little or no functional speech (LNFS) and severe physical disabilities a method to access electronic AAC systems that is faster, less demanding, more reliable and less partner-dependant than various other access options such as scanning or head-controlled access. Although eye gaze technology was initially mainly used for people who were literate and cognitively able, advances in this technology have enabled its application to persons with more diverse abilities, including preliterate children [1]. Messages on electronic AAC systems for preliterate children are typically encoded using pictorial (also called graphic) symbol systems such as Picture Communication Symbols (PCS), SybolStix or Widgit. 
Models, theories and definitions of disability have increasingly stressed that activity and participation limitations of persons with disability are a function not only of the person's skill levels, but of the interaction between the person's abilities and the barriers and opportunities present in the environment (e.g. social model of disability [2]; International Classification of Functioning, Disability and Health [3], participation model [4]). It follows that resourcelimited environments can significantly impede on the participation of persons with disability, as the limitations in body functioning and structure are exacerbated rather than ameliorated by environments that are unsupportive and inaccessible.

Bronfenbrenner's bioecological theory of human development [3] can provide a useful framework to describe not only the environment, but also the processes and interactions between the person and his/her context that ultimately influence functioning. These factors can present risks or opportunities at every level of the ecology. This model can therefore provide a useful framework for describing environmental influences that may facilitate or hinder the implementation of assistive technology as part of a rehabilitation plan for persons with disability.

This paper will focus on the implementation of eye gaze technology to access graphic-symbol based AAC systems for two children with dystonic cerebral palsy in South Africa. A section of Bronfenbrenner's theory, namely the model of the ecology as nested systems (micro-, meso-, exo- and macrosystems) will be used as a framework for highlighting the influences of the environment on the implementation of this technology.

\section{Background}

The Centre for Augmentative and Alternative Communication (AAC) at the University of 
Pretoria, South Africa, was established in 1990. This Centre, with eight full time staff members, is the only of its kind in the whole of Africa. The Centre's core responsibilities include presenting four different post graduate degree programmes and conducting research in the fields of augmentative and alternative communication, severe disability and early childhood intervention. In response to overwhelming community need, specialised training (short courses) is presented to professionals and parents as well as consultations and assessment to clients of all ages requiring AAC. Clients often travel some distance for an assessment at the Centre, as comprehensive AAC evaluations (consultations) are conducted, utilising the Centre's wide range of AAC devices, which cannot be found elsewhere on the continent.

As the Centre has very limited human resources to conduct follow-up support and intervention in the client's context, consultations with individuals requiring AAC are only conducted when the client is able to bring their support team to the assessment. The understanding is that the support team will carry forward any recommendations made during the consultation. The team should always include the family, care giving assistant and professional members of the team, including therapists and/or educators. Usually a once-off face to face consultation takes place with at least two centre staff members where an attempt is made to understand the client and family's needs, skills and abilities, as well as their resources and the environments within which they participate or would like to participate in order to determine suitable AAC interventions. The professional team from the Centre for AAC discusses its recommendations with the client and their team, and a detailed report providing intervention guidance as well as technology recommendations are provided to the team. Hereafter, the client's own team is responsible for the implementation of intervention strategies and overseeing procurement of any devices. The client's team is invited to discuss 
any difficulties with the Centre for AAC team, as they arise, and queries are mostly handled via telephone or email. Typically recommendations include low technology AAC interventions, such as paper-based picture boards, as well as variety of appropriate high technology AAC devices, such as dedicated speech generating devices or tablets, depending on the abilities and context of the client.

\section{Case reports}

After the Centre obtained an eye tracking device at the end of 2011, the professional team at the Centre for AAC has recommended the use of such a device to a handful of clients, including two young children with dystonic cerebral palsy. These two children have been provided with eye tracking devices after funds were raised in order to purchase them. Both girls were preliterate and able to use picture symbols to communicate at the time of the consultation. Neither had a formal low technology communication system in place at the time of assessment, but both were using eye gaze to communicate.

Since this technology is so new in South Africa and little knowledge exists on the success of its implementation, the first author conducted a follow-up visit to the contexts where children used their devices (one at home and the other at school) approximately 3 months after they received their device. The visits revealed that, despite good initial feature matching, neither child seemed to be utilising the technology fully, although the one child seemed to be doing better than the other. Interviews were conducted with family and support staff in order to identify both risks and opportunities for the participation, learning and resulting development of both children in their particular contexts. 


\section{Case 1:}

$\mathrm{C}$ is a 7-year-old girl with dystonic cerebral palsy. The functioning of all four of her limbs is significantly influenced by the fluctuating tone typical of this condition. She requires a full time personal assistant to attend to her daily needs, who is paid for by her parents. In addition to her physical difficulties, $\mathrm{C}$ was also diagnosed with severe bilateral hearing loss as a young child. She received bilateral cochlear implants at a young age. She lives with both parents, as well as two older brothers in a middle class neighbourhood near Pretoria. C's home language is Afrikaans, one of eleven official languages spoken in the country.

At the age of 5 years, $\mathrm{C}$ attended a consultation at the Centre for AAC. As part of a comprehensive $\mathrm{AAC}$ evaluation, $\mathrm{C}$ was given the opportunity to use eye gaze technology to control computer programs and understood the concept of utilising her eyes to communicate/activate cells on the screen immediately. She seemed to find the device very motivating and could not stop smiling while using the device. She pressed on through countless activities during the assessment showing her interest in the device. After fundraising for more than a year, her parents were able to purchase an eye gaze device for C.

C's school career has been marked by frequent changes and disappointments: she has attended three schools for children with special needs, including private and public schools. At all of these facilities the majority of staff had indicated that C's needs were too great to be accommodated into their classes, even when being attended to by her full time assistant. This has resulted in her leaving each school and has lead C's mother to keep her at home. Although C is required (by law) to attend school, suitable schooling could not be obtained for her. C's mother, together with her full time personal assistant, currently provide $\mathrm{C}$ with home based education focusing on literacy and mathematic skills. All educational activities are 
created especially for $\mathrm{C}$ by her mother in the Grid 2 programme and presented to $\mathrm{C}$ either by the mom, or C's assistant, neither having any formal training in education, AAC or severe disability. Neither national nor provincial departments of education provide any assistance to this family in the schooling of their child. $\mathrm{C}$ has not started using her eye gaze device for any communication purposes, as her mother finds that she can communicate her needs by various unaided methods, such as staring at required objects, as she did before.

Currently, $\mathrm{C}$ receives private speech and physiotherapy. She also receives horse riding therapy and therapeutic swimming, all of which the parents must pay for themselves.

\section{Case 2}

$\mathrm{N}$ is a young girl of 9 , also severely physically affected by dystonic cerebral palsy. She lives with both her parents, a little brother of 2 years, both her paternal grandparents as well as an uncle, in the family home in a middle class neighbourhood in Johannesburg, the largest metropolitan area in South Africa. N's home language is English.

$\mathrm{N}$ attends a small private school for disabled children that operates from the home of one of the teachers at the school. The school has only one class, with 2 full time trained teachers, and a maximum of seven children. When $\mathrm{N}$ reached school going age, N's parents were unable to find a suitable government funded school for their child, and they are now responsible for carrying the cost of her private schooling together with speech and oxygen therapy she currently receives.

Both of N's teachers have visited the centre for AAC, also with some of the other children in their school. N's eye gaze device is the first high technology device the teachers have used in 
their classroom, but both are very motivated and keen to utilise the device. At the time of the first author's visit to N's school, $\mathrm{N}$ had started using her device as communication device within certain preselected activities within the classroom. Her teachers, together with her mother have managed to programme the Grid 2 software programme to be used with the eye gaze device. They have managed to engage $\mathrm{N}$ in using her device to communicate during certain activities, for example choosing the song the class will sing from picture symbols displayed on the device. An English voice is used for N.

\section{Discussion}

The case reports suggest that, in spite of the initial barrier of the acquisition of the expensive eye gaze technology having been overcome, numerous factors within the children's proximal and distal environment still exist that influence the successful implementation of the technology. An analysis according to of Bronfenbrenner's bioecological [5] model can aid our understanding of the risks and opportunities present in the ecology that may influence the participation and ultimately the outcomes for both children and their families.

\section{Microsystem}

The microsystem describes the immediate environments within which the child functions. This may include the home environment as well as educational settings. The microsystem can be conceptualized as a synergy of different components as depicted in figure 1(adapted from [6]). This model is similar to the Human Activity Assistive Technology (HAAT) model [7], except that the prominence of the partner is highlighted in the former, due to the fact that participation in interactive rather than solitary activities is the focus of AAC intervention. 


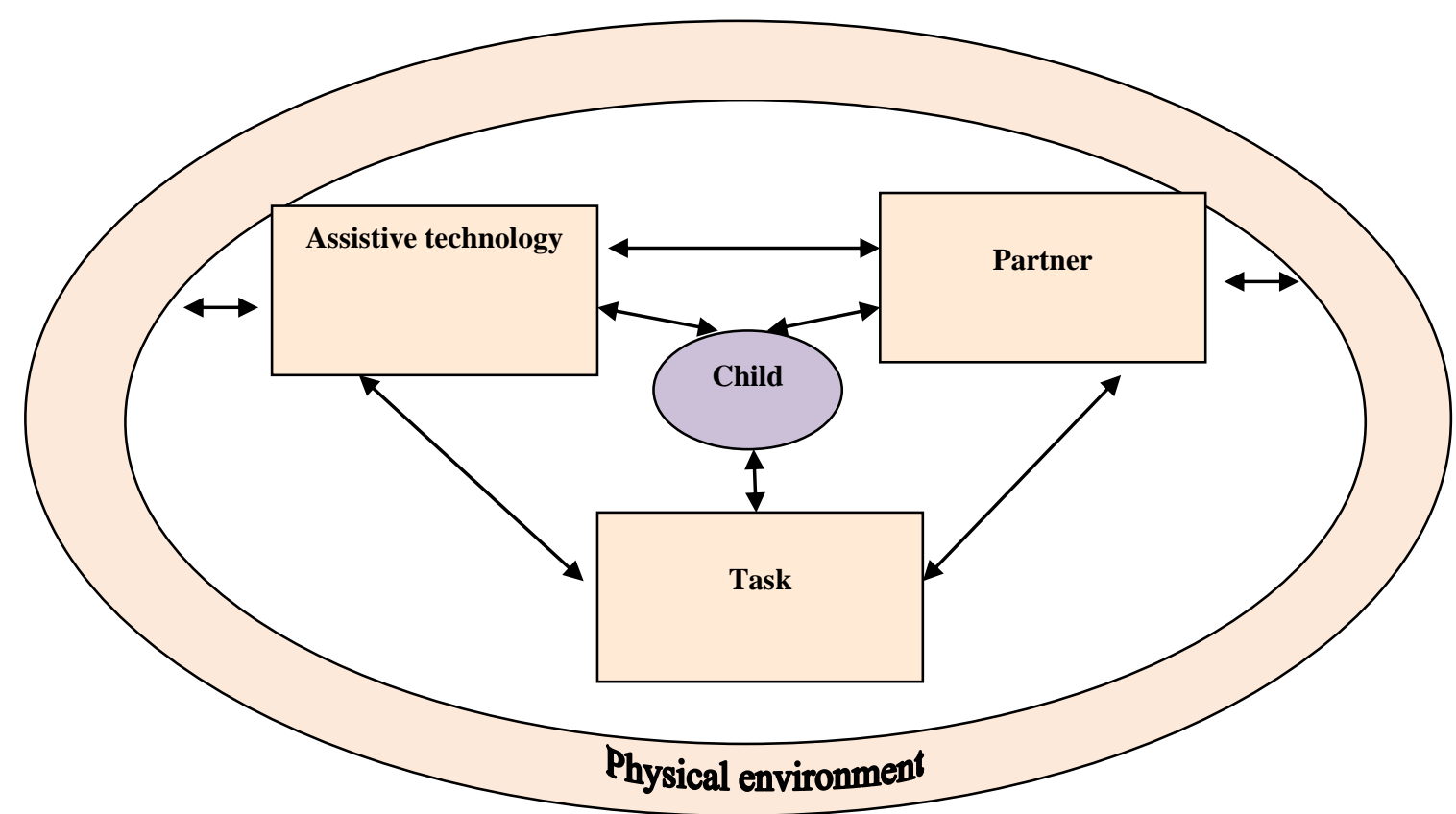

Figure 1: Components of the microsystem.

The success of interactions and level of participation in the microsystem is determined not only by the ability or integrity of these components, but also by the extent to which their limitations can be compensated for by the adaptability and flexibility of the other components.

\section{Assistive technology}

The initial assessment suggested that both children were well able to use the eye gaze system to access computer activities, and the system seemed a good match for their abilities. Both families also continued with various trials of the technology at the vendor before purchasing the system of their choice. The systems acquired by both families consisted of a separate eye gaze module that could be attached with magnetic strips to an existing computer screen to allow the computer to be accessed via eye gaze. These systems are less pricy than integrated systems where the eye gaze access technology is incorporated into a tablet computer. Both families also acquired mounting equipment - N's family acquired a mounting arm that could 
be attached to a table, while C's family acquired a stand-alone mounting on wheels that would enable the system to be moved around in the house. The families also bought the Grid 2 communication software and loaded it onto the computer, to transform the computer into a graphic symbol-based speech generating device. Once again, this seemed a good choice given the participants' ability to use symbols for communication, as determined in the initial consultation.

In spite of a seemingly good match between participant abilities and the assistive technology, both families reported challenges in its implementation. These included problems with technology functioning (e.g. the eye gaze module not always reading the eyes of the girls, even though they appeared to be within the track box of the device), sturdiness (the eye gaze module seemed to detach from the screen very easily on contact, causing concern regarding safety) and mounting (the space available did not allow for N's table top mounting to be used, and precluded $\mathrm{C}$ from using the stand-alone mounting to move the device around). The implementation of the technology in real-life situations was clearly more challenging than its use in structured assessment contexts. Problems with device implementation are not unique to resource-limited environments [8]. However, lack of financial support for the acquisition of the system precluded the families from obtaining more integrated, robust, portable systems. In resourced environments this may have been possible and led to a better match between not only the person's abilities and the technology, but also the partner's skills and the constraints of the physical environment.

Furthermore, C's mother felt disillusioned about the possibilities of the technology to ameliorate C's communication challenges. As C could not discriminate well visually among more than 4 to 6 cells on her screen, access to a larger vocabulary would have required a 
number of grids, interlinked by so-called 'jump cells' that enable navigation to another grid. C's mother felt that programming the amount of vocabulary which she felt was needed for functional communication in numerous interlinked grids sized 4 to 6 cells was too cumbersome for her, and the use of such a system with intense navigational demands would be too cumbersome for $\mathrm{C}$. She indicated that their established method of communication (using yes/no questions, $\mathrm{C}$ staring at objects in the environment) was quicker, more accurate and less frustrating to all involved. She indicated that they would start using the system for communication purposes once $\mathrm{C}$ was literate, and only needed access to the 26 letters of the alphabet and a few punctuation marks to communicate anything she wanted to say.

Using AAC systems that are based on single-meaning graphic symbols such as Widgit or PCS requires visual, cognitive and linguistic skills that may be underestimated by those who design, customize or prescribe them [9-11]. Accessing single-meaning symbols (i.e. one concept - one location) places significant demands on memory and/or visual search skills, as the person using the system navigates through various screens and/or scans through an array of items [10-12].

C's mother did feel that eye gaze access opened up C's opportunities to take part in educational and literacy activities, which she programmed into the Grid 2. She decided to teach C English literacy skills, making use of an English voice synthesizer rather than the one prototype Afrikaans voice synthesizer available for Windows as she felt that the pronunciation of the latter synthesizer was not accurate, which would disadvantage $\mathrm{C}$ in learning to spell. $\mathrm{C}$ was therefore learning literacy in a second language, a process that is more difficult than learning literacy in one's home language [13]. 
N's teachers together with her parents, had set up a few activity-specific vocabulary grids on the system, and $\mathrm{N}$ successfully used these to answer questions and make choices in class when prompted to do so. She did not yet independently navigate through different screens, and depended on the adults to do this for her. Although $\mathrm{N}$ clearly needed lots of support and was not using the system to initiate communication yet, she had at least started to experience herself as an aided communicator with a voice.

\section{Partner}

The 'more competent interactive partner' [14] may be the most important factor in promoting successful interaction and participation of preliterate AAC users. Not only do partners need to appropriately scaffold communicative exchanges [14], but they also typically need to take responsibility for ensuring optimal functioning of the system, adapting the task and materials as well as setting up the environment in a way that ensures access. Both N's teachers and C's mother felt that they needed additional training to position the system correctly and to control lighting in order for the eye gaze access to function optimally. N's mother was a computer programmer, and she found it relatively easy to learn how to program grids for N. N's teachers indicated which vocabulary they wanted her to program, and she would then include this in the grids she made. C's mother also taught herself how to program grids, but this may have been a steeper learning curve for her. The vendor had given some training on the set-up of the eye gaze module as well as the programming of the software, and even followed up the implementation of the technology in C's home. However, as vendors are not supported by large-scale sales to government agencies (e.g. health and education departments), the companies tend to be small and capacity to follow up on implementation remains limited. 
Both parents as well as N's teachers felt that selecting and arranging vocabulary was challenging - a task that they did not feel adequately trained for. In fact, few empiricallybased guidelines exist even for AAC professionals to select and arrange vocabulary [15], and these issues remain challenges for all those who support communicators who use singlemeaning graphic symbols. Due to the relatively small population using technology-based AAC in South Africa, few professionals can exclusively focus on this population, and few become experts in this area.

\section{Environment}

In both cases, factors related to the physical environment, such as the space available, the organization of this space and issues of lighting were factors that complicated the use of the technology across contexts and situations. Both N's teachers and C's mother suspected that lighting influenced the way that the eye gaze technology was able to read the eyes of the children, but did not know how to control for this. Neither mounting was used as intended. N's teachers found that the mounting acquired by her parents complicated N's positioning in relation to the rest of the class and the available space, and therefore preferred to prop up her computer screen on a table without the mounting. The fear that peers might break the technology resulted in its positioning in a specific corner of the classroom, away from the other children. C's mother reported that the size of the stand-alone mounting in relation to the size of their rooms and doors precluded them moving the system around in the house, and therefore the system remained in one place.

\section{Task}

It is clear from the above discussion that the constraints of the children's skills, the assistive technology available to them and the skills and training of their partners and those who set up 
their systems limited the communication tasks or situations in which the system was used. C did not use the system for any communication tasks, but rather for literacy training. $\mathrm{N}$ did use the system for communication situations where her contribution was easily predictable (e.g., song choices) and where the interaction did not have a high demand for speed, to allow partners to set up her screen and give her an opportunity to access her contribution. In both cases, guidance seemed to be needed on how to expand the repertoire of activities during which the assistive technology could be used.

\section{Mesosystem}

The mesosystem encompasses the quality and quantity of connections that exist between different microsystems [16]. Ideally, the link between the home environment (where children typically spend most of their time) and the settings where any intervention is implemented (such as school or therapy) should be very strong. Strong connections in the mesosytem will reduce risks that negatively influence children's functioning and promote their development and the use of their device. Therefore, good communication between, for example, the class teacher and the parent is necessary in order to address technical problems with the system in a timely manner. Teamwork between therapists, parents, teachers and personal assistants is furthermore important to ensure that the vocabulary in the system is appropriate, that partners have consistent expectations of the child and that strategies that are particularly helpful to elicit successful use of the system and maximum participation are shared amongst partners. The latter may include positioning, allowing adequate response time, and using appropriate cues and prompts to elicit communication.

Because $\mathrm{C}$ did not attend school outside of the home, this family may have been at risk of becoming somewhat isolated in their implementation of eye gaze technology. Although the relationship between the speech therapist and parents appeared to be good, AAC goals did 
not seem to be integrated with the goals set out for speech therapy. Due to challenges in transporting the device plus its mounting, the device was not taken along to speech therapy. The family also preferred to leave the device at home when visiting family, and for practical reasons it was not taken to horse riding or swimming. This limited the number of interactions and possible sources of support to this family, which may have posed a risk to the participation of this child and her resulting development.

In N's case, the relationship between the teachers (at the microsystem of the school) and the parents (at the microsystem of the family and home) appeared to be very strong. Communication appeared to happen frequently, with the mother (with her beneficial background in computer programming) programming specific grids for the device according to the needs of the teachers. The parents also took the device home on a daily basis and tried to use it for half an hour every evening, playing games practicing eye gaze with their daughter. However, the relationship with the speech therapist did not seem good. The family and educational goals (including the use of AAC) did not appear to be incorporated into speech therapy intervention. Therefore, the family did not feel that $\mathrm{N}$ benefitted from this intervention and they experienced very little support from the speech and language therapist.

When comparing the two cases, the difference in the functional use of the eye gaze devices may be contributed partly to the significant difference between the support experienced between the two cases at this level of the ecology. $\mathrm{N}$ may have been benefitting from stronger connections in her mesosystem with teachers and parents supporting each other in implementation, while C's family seemed isolated and alone in trying to implement the technology. 


\section{Exosystem}

The exosystem can be described as those settings that influence the child's development, but where the child does not participate directly [16]. Examples of factors from the exosystem might include the work environment of parents of a child with LNFS and severe physical disabilities, or the school board of the child's school. The exosystem has an influence on the participation and resulting development of a child, as it influences the quality of the interactions that occur within the microsystem of the child. If parents work in a supportive environment, receive good wages and have flexible and reasonable working hours, it is of benefit to their children. Parents could, for example, have more time to interact with the child or to programme the child's device. They might have more patience while communicating and be prepared to wait for the child's response more often that they would have, if they were constantly exhausted, busy or stressed from work. Obviously, more positive communication experiences will lead to better use of the device.

Furthermore, device purchase and upkeep is costly, especially for eye gaze technology. In a developing context such technology is typically imported, adding to the cost. Local importers of the technology are very limited within the country, resulting in little competition between suppliers, leaving consumers with a very limited choice in where they purchase or service their devices. Eye gaze optimized software programmes, such as games to teach mouse control, are also very expensive. A good income may enable purchase and regular maintenance of the most appropriate system and software.

In both cases, the work environments of the parents formed part of the exosystem surrounding the child. A positive factor in both cases was that all parents were earning an income and were able to contribute financially to their households. N's father was self- 
employed, operating a small import company. Her mother was a computer programmer for a large local bank. Both parents reported that they had time off in the evenings to spend with $\mathrm{N}$. C's father owned his own business, with her mother employed in the business as bookkeeper. C's mother specifically had a flexible timetable that allowed her to attend to her daughter's complex needs.

Policies and decisions made on an exosystemic level may also influence the successful use of an eye gaze device. In the case of $\mathrm{C}$, the decisions of various school boards to exclude her from their school, had directly lead to her parent's decision to home school her. Not only did her parents now bear the burden of creating an inclusive learning environment tailored especially to their daughter's needs, but they were also losing the support they could have obtained from school structures in terms of shared expertise and guidance to parents. Even informal supportive connections, such as with other parents of children in the school that may have faced similar challenges, were lost to this family.

The absence of important support structures in the exosystem could have posed a risk to both children and may have influenced how they functioned with their devices within their various microsystems. Neither family had ever attended any support groups, as such groups for families or persons using AAC or for people with severe disabilities, as these scarcely exist in the South African context. Neither family had received any counselling or training in coping with the emotional burden associated with caring for a severely disabled child. Very little training in AAC had been received or was even available to the family or professionals providing services to them. 


\section{Macrosystem}

The demographic, institutional and ideological patterns that are engrained within a specific culture form the macrosystem of a child [16]. Factors from the macrosystem may influence the child's effective use of a device, or whether acquisition of a device is even a possibility for a specific child. While both the children in the case studies were able to obtain devices, most are not as fortunate.

South Africa is a developing country with various social and economic challenges. An estimated 5 to $6 \%$ of the population have moderate to severe disabilities [17], many of whom do not have access to even basic rehabilitation services. Although access to health care and basic education are granted as human rights to all South African citizens [18], the realization of these rights are subject to the internal limitations of the resources available within the system at any point in time.

Public health services may include the provision of certain assistive devices (excluding communication devices), such as wheelchairs and hearing aids - but this provision is subject to availability. More affluent people, such as the middle class families described in the cases, typically belong to private medical aids and visit private health practitioners. Medical aids generally do not pay for high technology devices, such as eye tracking devices. Clients thus need to pay for such devices themselves or raise funds from corporate or private donors to enable the purchasing of such devices. Both the children in the case studies were able to obtain their devices after substantial contributions from private donors.

Due to limited access to high technology devices, local professionals have very little exposure to and experience with high technology devices, such as eye gaze devices. Most 
local therapists (including some of the professionals providing services to the case studies) have never heard of eye gaze technology to access AAC. AAC in itself is an unfamiliar term to many, with AAC only recently being incorporated into speech therapy training in universities throughout the country. Occupational and physiotherapists, as well as teachers receive no training on this topic in their undergraduate studies. As a result, even a person with substantial financial resources may very likely be unable to obtain the professional support they require to fully implement eye gaze technology.

According to the South African Schools Act of 1996 [19], school attendance is mandatory for children aged 7 to 15 . Only on request of a parent may school authorities agree to exempt a child with very severe medical conditions or disabilities from school attendance. It follows that education should, at least in theory, be available to all children in the country. While the National Department of Education has established the inclusion of children with disabilities into mainstream schools as a goal in White Paper 6 [20], very little has happened to make this a reality. Separate schools for learners with special educational needs are still the norm. The admission policies at these schools often preclude children with multiple or severe disability from enrolling. Neither $\mathrm{N}$ nor $\mathrm{C}$ was included into the public school system. $\mathrm{N}$ attended a private school, which was financed by the school fees paid by parents. In C's case her family had not found either a public or private school suitable for her or willing to accommodate her, and consequently the family took over the responsibility for schooling themselves.

In South Africa, the medical model still significantly influences perceptions of members of society regarding people with disabilities. According to this model, the inabilities of the child with the disability should be assessed and addressed in order for the person to function in society. The focus is placed on the shortcomings, rather than the assets of the child. A 
separatist system (e.g. special education, homes for children and adults with disability) is still very prevalent, and there is little pressure for society to become more accommodating through environmental and attitudinal changes (e.g. increasing physical access to public spaces, and increased acceptance and respect towards people with disability by the general public). Families of children with disabilities often experience the ostracism alongside their child with a disability as the community participation of the family is complicated by an inaccessible environment as well as societal attitudes. Both $\mathrm{N}$ and $\mathrm{C}$ participated only in a very limited way in community activities (e.g. shopping) due to physical and attitudinal barriers. These factors obviously limited the implementation of assistive technology in various environments. Moreover, they also limited their communication partners to close family (and in N's case, her teachers and peers at school). As familiar partners tend to have established ways of communication, the need to rely on AAC is also reduced.

\section{Conclusion}

The discussed cases have highlighted several important aspects from the ecology that could impact on a preliterate child's use of an eye gaze device. Throughout the discussion of both case studies and the risks and strengths experienced in the wider ecological systems, it was evident that families experience limited support from the environment. When complicated assistive technology such as graphic symbol-based AAC technology accessed through eye gaze is introduced into the family or educational microsystem, it seems unrealistic to expect this system to cope without the provision of support from more distal systems. In resourcelimited environments, the biggest challenge in assistive technology implementation is often seen to be the acquisition of the assistive technology. These cases illustrate that the absence of infrastructure for support of the implementation of the technology is a further risk factor that can hinder implementation. 
From the discussion of the microsystem the importance for interventionists to address practical issues stemming from the immediate environment where the assistive technology will be used was highlighted. In addition to time spent with the user of the eye gaze technology in a consultation room, visits to home or school are indicated, as well as regular problem solving sessions with the primary communication partners. This will create opportunities to address practical implementation issues, such as lighting or positioning that may influence the effective use of the device but could easily be overlooked by service providers.

When providing services to clients in resource limited environments, interventionists need to be aware of the added strain that the lack of environmental support structures can place on the family in their effort to sustain the use of assistive technology. Dunst, Trivette and Deal [21] describe the resource-based approach that could be used in guiding the family in identifying the resources or strengths that could assist them in accessing the support they require. Within resource-limited environments, this support may often be informal (e.g. community members) rather than formal (e.g. professional service providers). Examples may be persons with computer knowledge that may be contacted to assist in programming devices, or neighbours that could act as communication partners to children using AAC.

The lack of collaboration between service providers, difficulties in sourcing information/training as well as the absence of a shared goal for intervention could be addressed by initiatives to bring together all role players for a specific case for meetings (even if only occasionally possible). As all role players (interventionists, vendors, family etc.) will most likely not be employed by the same department or system, this may become 
the responsibility of a parent/partner or one highly involved service provider. This would provide the opportunity for the establishment of an integrated plan for intervention and could set the stage for information sharing and multiskilling of different role players in order to become more competent with different aspects of the technology used [22].

Importantly, for an interventionist providing services in a resource limited context, the focus of intervention can clearly not only be on providing services to an individual client and their family. Establishing contact between families that are in the process of implementing similar technology may be one strategy to increase technical and emotional support and decrease isolation. Strategies such as these will broaden the intervention process and lead to the expansion of an infrastructure for support also accessible to other community members [23]. In this way community capacity is build, and clients that intend to use eye gaze technology and their families may be better supported in future. Community groups such as these may also strengthen the wider disability sector in the country and provide feedback to government regarding policy and practice that influence the use of assistive technology in the community.

Research into the barriers for the use of assistive technology within all levels of the ecology as highlighted by the case discussion is indicated, and has been confirmed as a major need within the developing context [24].

\section{Declaration of interest:}

The authors report no conflict of interest. 


\section{Reference list:}

1. Donegan M, Morris J D, Corno F, Signorile I, Chiò A, Pasian V, Vignola A, Buchholz M, Holmqvist E. Understanding users and their needs. Univ. Access Inf. Soc. 2009:259-275.

2. McEwan C, Butler R. Disability and development: different models, different places. Geography Compass. 2000:448-466.

3. World Health Organization (WHO) [Internet]. International Classification of Functioning, Disability and Health. Geneva, Switzerland; 2001 [cited2014 Jan 29]; Available from http://www.who.int/clas

4. Beukelman DR, Mirenda P. Augmentative and Alternative Communication. Supporting Children and Adults with Complex Communication Needs. 3rd ed. Baltimore: Paul H Brookes; 2005.

5. Bronfenbrenner U, Morris L. The bioecological model of human development. In: Lerner R M, Damon W, editors. Handbook of Child Psychology. 6th ed. Hoboken, NJ: John Wiley \& Sons; 2006. p793-828.

6. Tönsing KM. Using a matrix strategy to teach graphic symbol combinations to children with limited speech during shared storybook reading. [Doctoral Thesis]. Pretoria, South Africa: University of Pretoria; 2012.

7. Cook AM, Polgar JM., Livingston, NJ. Need- and Task-based design and evaluation. In: Oishi, MMK, Michell, IM, Van der Loos HFM. Design and use of assistive technology. Social, technical, ethical and economic challenges. New York: Springer; 2010: 41-47.

8. O’Rourke P, Ekins R, Timmins B, Timmins F, Long S, Coyle E. Crucial design issues for special access technology; a Delphi study. Disabil Rehabil. 2014; 9: 48-59.

9. Boyer C, Trudeau N, Sutton A. Performance of children with typical development when reading and interpreting graphic-symbol sequences. Augment Altern Comm. 2012; 28: 96-105.

10. Dukhovney E, Soto G. Speech generating devices and modality of short-term word storage. Augment Altern Comm. 2013; 29:246-258.

11. Thistle JJ, Wilkinson KM. Working memory demands of aided augmentative and alternative communication for individuals with developmental disabilities. Augment Altern Comm. 2013; 29: 235 245.

12. Herold M. A comparison of the rate and accuracy of symbol location on visual displays using colour-coded alphabetic and categorisation strategies in Grade 1 to 3 children [dissertation]. Pretoria, South Africa: University of Pretoria; 2012. 192p. Available from http://upetd.up.ac.za/thesis/available/etd-10142012$\underline{183928 / \text { unrestricted/ }}$ 
13. Ramirez AG. Literacy acquisition among second-language learners. In: Ferdman, BM, Weber RM, Ramirez AG, editors. Literacy across languages. New York: State University of New York; 1994; p75-102.

14. Renner G. The development of communication with alternative means from Vygotsky's cultural historical perspective. In: Von Tetzchner S, Grove N. editors. Augmentative andAlternative Communication: Developmental Issues. London, United Kingdom: Whurr; 2003; p 67-82.

15. Fallon K, Light J, Achenbach, A. The semantic organization patterns of young children: implications for augmentative and alternative communication. Augment Altern Comm. 2003; 19: 74-85.

16. Garbarino J, Ganzel B. The human ecology of early risk. In: Shonkoff JP, Meisels SJ, editors. Handbook of Early Childhood Intervention. 2nd ed. Cambridge: Cambridge University Press; 2000: p76-93.

17. Schneider M, Saloojee G. Monitoring childhood disability. In: Dawes A, Bray R, Van der Merwe A, editors. Monitoring Child well-being: A South African rights-based approach. Cape Town, South Africa: HSCR Press; 2007:p191 - 211.

18. Constitution of the Republic of South Africa [Internet]. 1996-[cited 2014 Jan 2014]; Available from http://www.info.gov.za/documents/constitution/1996/a108-96.pdf

19. South African Schools Act, Act 84 of 1996 [Internet]. 1996-[cited 2014 Jan 2014]; Available from http://www.info.gov.za/acts/1996/a84-96.pdf

20. Education White paper 6: Special Needs Education. Building an inclusive Education and Training System [Internet]. 2001-[cited 2014 Jan 2014]; Available fromhttp://www.info.gov.za/whitepapers/2001/educ6.pdf

21. Dunst CJ, Trivette CM, Deal, A. Enabling and empowering families. Cambridge, MA: Brookline Books; 1988.

22. Bornman J, Uys, CJE. Multiskilling in AAC intervention. In: E Alant, LL Lloyd, editors. Augmentative and alternative communication and severe disabilities. London, United Kingdom: Whurr; 2006.

23. Alant E. Support-based AAC intervention. In: E Alant, LL Lloyd, editors. Augmentative and alternative communication and severe disabilities. London, United Kingdom: Whurr; 2006.

24. Tomlinson M, Swartz L, Officer A, Chan KY, Rudan I, Saxena S. Research priorities for health of people with disabilities: an expert opinion exercise. Lancet. 2009; 374: 1857-1862. 